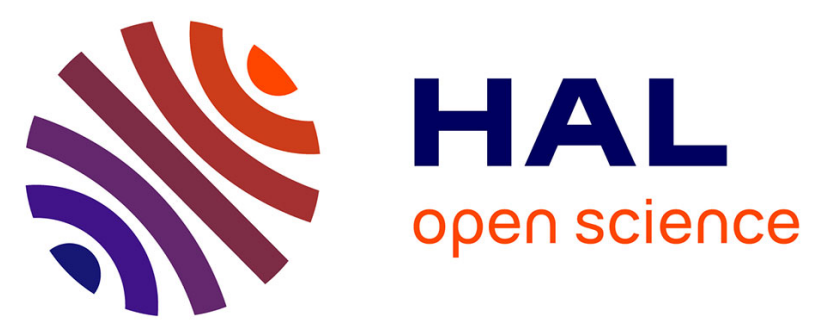

\title{
Approaches for the Integration of the Social and Environmental Dimensions of Sustainability in Manufacturing Companies
}

\author{
Paul Schönsleben, Felix Friemann, Manuel Rippel
}

\section{- To cite this version:}

Paul Schönsleben, Felix Friemann, Manuel Rippel. Approaches for the Integration of the Social and Environmental Dimensions of Sustainability in Manufacturing Companies. IFIP International Conference on Advances in Production Management Systems (APMS), Sep 2016, Iguassu Falls, Brazil. pp.868-875, 10.1007/978-3-319-51133-7_102 . hal-01615751

\author{
HAL Id: hal-01615751 \\ https://hal.inria.fr/hal-01615751
}

Submitted on 12 Oct 2017

HAL is a multi-disciplinary open access archive for the deposit and dissemination of scientific research documents, whether they are published or not. The documents may come from teaching and research institutions in France or abroad, or from public or private research centers.
L'archive ouverte pluridisciplinaire $\mathbf{H A L}$, est destinée au dépôt et à la diffusion de documents scientifiques de niveau recherche, publiés ou non, émanant des établissements d'enseignement et de recherche français ou étrangers, des laboratoires publics ou privés. 


\title{
Approaches for the Integration of the Social and Environmental Dimensions of Sustainability in Manufacturing Companies
}

\author{
Paul Schönsleben*, Felix Friemann, and Manuel Rippel \\ ETH Zurich, BWI Center for Industrial Management, Zurich, Switzerland \\ pschoensleben@ethz.ch
}

\begin{abstract}
Social, environmental and economic challenges such as poverty, sub-standard working conditions, climate change, resource scarcity or environmental depletion lead to a rising importance of a multi-dimensional consideration of sustainability in manufacturing companies. The strong impact of manufacturing on humans and the environment necessitates the integration of social and environmental aspects in addition to the currently predominant focus on economic results. This paper exploits the potential of approaches with a cost, result and life-time perspective in order to obtain a well-balanced and measurable view on sustainability of manufacturing companies in industrial practice.
\end{abstract}

Keywords: Total Cost of Ownership - Triple Bottom Line - Life-Cycle

\section{Introduction}

The effective and efficient manufacturing of goods has contributed significantly to rising living standards by meeting needs of society, advancing the development of infrastructure and education as well as offering employment and income. While the main focus of decision makers in manufacturing companies was on economic and technological issues, rising environmental pollution, scarcity of resources as well as the impact of globalization on local prosperity and working conditions started to change society and business values [1]. Sutherland et al. examine the activities of manufacturing companies and its effects on individuals and stakeholder groups with regard to social issues, such as corporate social responsibility (CSR), extended producer responsibility (EPR), outsourcing/reshoring [2]. The challenge for companies is to tackle the assumed dichotomy between competitive, environmentally friendly and socially responsible operations. This paper aims to highlight approaches that address the integration of the social dimension with the economic and environmental dimensions of sustainability. Thus, approaches with three different perspectives are presented in the following. Examples from industrial practice are provided in the third section in order to illustrate how manufacturing companies implement the integration of social and environmental dimensions on sustainability in varying degrees of detail and at different levels. The fourth section concludes this paper and presents an outlook. 


\section{Approaches that Integrate Sustainability Dimensions}

Regarding integrating the social and environmental dimensions of sustainability into manufacturing, this section reveals three approaches of varying degrees of detail with a cost, result or life-time perspective. The first approach, named "Total cost of ownership (TCO)", is widely used, but the extent to which it takes comprehensive ways of thinking and acting in terms of sustainability into account is minimal. The second approach, labeled as "Triple Bottom Line", goes much further, but also involves considerably more integration of sustainability concepts into corporate acting. The third approach, known as "Life-Cycle Sustainability Assessment (LCSA)", shows developments and future directions of measuring the social dimension of sustainability.

\subsection{Cost Perspective: Total Cost of Ownership (TCO)}

When taking decisions in a company, the cost perspective is an important driver for decisions. The favored alternative can vary depending on the temporal preference of the decision maker, e.g., whether they have a preference for a short-term or a long-term payback. The practical approach for decision support, the "Total cost of ownership (TCO)", converts relevant (both monetary and nonmonetary) considerations, criteria and factors for decision making into costs. Different cost elements and its categories (I-IV) are depicted in Figure 1. The TCO approach supports globally active manufacturing companies to decide on make-or-buy alternatives (including in-house, outsourcing, offshoring) or to choose between different potential suppliers [3].

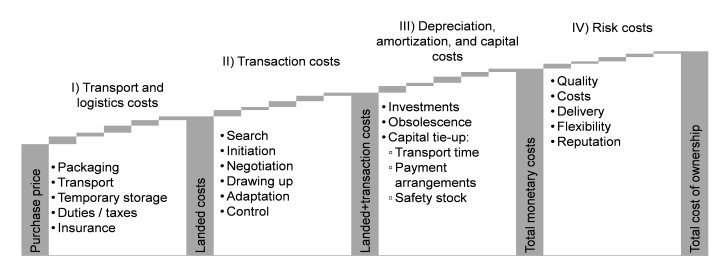

Fig. 1. Elements and categories of costs within Total Cost of Ownership (Source: [4])

\subsection{Result Perspective: Triple Bottom Line (TBL)}

Nowadays, consumer awareness around sustainable consumption is increasing [5]. "Triple bottom line (TBL)" mindset (or three Ps: people, planet, prosperity) holistically takes into account the implications on environment, society, and economy of a product and its manufacturing [5,2]. An approach to address sustainability is full cost accounting. In a review of 4381 papers, ten full cost accounting methods with a diverse level of development and consistency in application were identified [6]. Investment and return should not be a tradeoff 
"between social and financial interest, but rather the pursuit of an embedded value proposition composed of both" [7].

\subsection{Life-time Perspective: Comprehensive Life Cycle Assessment (LCA)}

Besides the previously introduced approaches, there is an active community in academia developing alternatives for assessing sustainability in a detailed and comprehensive way. This already has an impact on the thinking of scientists and practitioners of globally active manufacturing companies. Several authors dealt with the topic of merging life-cycle assessments (LCA) with other assessments combining all three sustainability pillars (environmental, economic and social) results in a "life-cycle sustainability assessment (LCSA)". Finkbeiner et al. conclude that LCSA "has to deal with the trade-off between validity and applicability" [8]. They propose a way to present LCSA results more effectively and efficiently to real world decision-makers in public and private organizations $[8,9]$.

\section{Social and Environmental Dimensions in Industrial Practice}

The above introduced approaches of varying degrees of detail are explored here at the micro (company) level or at the macro (economy) level. Applications from industrial practice are presented related to TCO in a cost perspective, to TBL in a result perspective and to LCSA in a life-time perspective.

\subsection{Examples for the Cost Perspective in Industrial Practice}

The TCO approach is rather straightforward and was particularly developed for practical usability. It can be easily adapted to the managerial targets of a specific manufacturing company related to social and environmental business priorities by changing or extending cost elements and categories. Bremen et al. identified the importance of different TCO elements (Figure 2) by conducting a survey with 178 Swiss companies from the machinery, electrical and metal industries in $2010[4,3]$. The survey revealed related to the social dimension of sustainability that the risk of damaged reputation (lowest bar in Figure 2) was still only of average importance compared to direct economic factors at this point of time. Basically, the TCO approach shows the limitations when trying to include the environmental and social aspects into the decisions of a short-term motivated manager.

\subsection{Examples for the Result Perspective in Industrial Practice}

In the following a small subset of frameworks, standards and indices is presented, showing examples of how sustainability (reporting) is done in practice today. To 


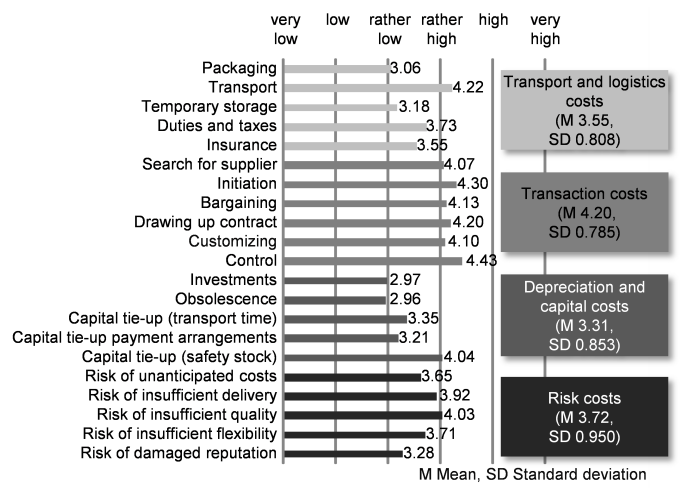

Fig. 2. Importance of the elements of the TCO (Source: $[4,3]$ )

Table 1. Example indicator set for sustainability assessment according to [8]

\begin{tabular}{|c|c|c|}
\hline $\begin{array}{c}\text { Life cycle } \\
\text { costing indicators }\end{array}$ & $\begin{array}{l}\text { Environmental } \\
\text { indicators }\end{array}$ & $\begin{array}{c}\text { Social } \\
\text { indicators }\end{array}$ \\
\hline Extraction costs & Embodied energy & Salary per employee \\
\hline Manufacturing costs & Global warming potential & $\%$ of female workers \\
\hline Finishing costs & Human toxicity potential & $\begin{array}{l}\% \text { of females at the administra- } \\
\text { tion level }\end{array}$ \\
\hline Waste disposal costs & Photochemical oxidation & $\begin{array}{l}\% \text { of employees with limited } \\
\text { contracts }\end{array}$ \\
\hline Electricity costs & Acidification & $\begin{array}{l}\% \text { of workers with yearly } \\
\text { check up }\end{array}$ \\
\hline Equipment costs & Eutrophication & Number of accidents \\
\hline Revenues & Abiotic depletion & Percentage of child labor \\
\hline Fuel costs & Ozone layer depletion & Number of discrimination cases \\
\hline Raw material costs & Terrestrial eco toxicity & Social benefits per employee \\
\hline
\end{tabular}

better understand environmental and social indicators, examples are shown in Table 1. The awareness from various stakeholders for TBL thinking and acting becomes evident when looking at the increasing effort of multinational corporations related to Corporate Social Responsibility (CSR). Sustainable behavior by corporates should be communicated and positively recognized. In Germany, for example, politics started to recognize the importance of these efforts recently and started to award a CSR award in 2013 [10]. In a survey conducted by Ernst \& Young, the groups with the most influence on the organization's sustainability strategy were customers and employees, while the most important principal objectives of a sustainability strategy were adding value, identifying and mitigating risks and obtaining competitive advantages [11].

The Global Reporting Initiative (GRI) is "the best-known framework for voluntary reporting of environmental and social performance by business world- 
wide" [12]. The extent of sustainability efforts is limited by company size. Most of the companies that report according to the GRI are large multinational corporations, while small and medium size companies (SMEs) are barely represented [12]. Also, the previously mentioned CSR award in Germany is differentiated by size of the company ( $1-49$ employees, 50 - 499 employees, $500-4,999$ employees, $>5,000$ employees), recognizing that small and medium companies often do not have the knowledge and resources to work on CSR reporting as thoroughly as bigger corporations. Literature accordingly notes: "the sucess of widespread adoption of sustainability management tools rests upon two key factors: raising awareness of tools with SME managers and promoting the relative benefits from the implementation tools" [13].

An example, which is currently applied in industrial practice, for the above mentioned full cost accounting method is the integrated profit and loss statement (IPL) of LafargeHolcim Ltd. [14], the global leader in the building materials industry (cement, concrete, aggregates, and asphalt). LafargeHolcim has been included in the Dow Jones Sustainability Index for more than 10 consecutive years. The goal of this index is to track financial performance of best-in-class companies worldwide assessing eco-nomic, environmental and social criteria with a focus on long-term shareholder value [15]. The IPL of LafargeHolcim was introduced in 2014 for the first time in an effort to quantitatively measure the TBL [14]. Figure 3 shows the IPL as a waterfall chart, which represents the different indicators that have an impact on the TBL. Lafarge-Holcim indicate that the "Triple bottom line can be used to assess opportunities beyond compliance", whereby the corporate mentions "Compliance with governance, social and environmental requirements and standards" [14]. Basically, the IPL emphasizes the company's objective in measuring its sustainability aspirations in a consistent way and to measure its progress over time. Furthermore, it can already be used "to identify where 1 US dollar invested would bring the highest societal return" [14].

Sustainability reporting can be misused to "greenwash" the image of a company. To prevent this, there is a "need for reporting transparency, inclusiveness, completeness, relevance, and auditability" [16]. Accordingly, more than $80 \%$ of respondents from the aforementioned survey answered that assurance will add credibility to a sustainability report and reporting in a "relevant, comparable and meaningful way" is a key for a high credibility [11]. Still, we are far from measuring and communicating sustainability efforts in a comparable way: different frameworks and standards exist for corporate sustainability reporting, as well as a variety of different ratings and indi-ces. The examples show advanced efforts from multinational corporations that still encounter problems in identifying and aggregating the right measurement variables.

\subsection{Examples for the Life-time Perspective in Industrial Practice}

Rametsteiner et al. [16] analyze the following three science-led and two intergovernmental-led processes and ascertain that "a number of sustainability indicator development processes have been initiated within large research projects 


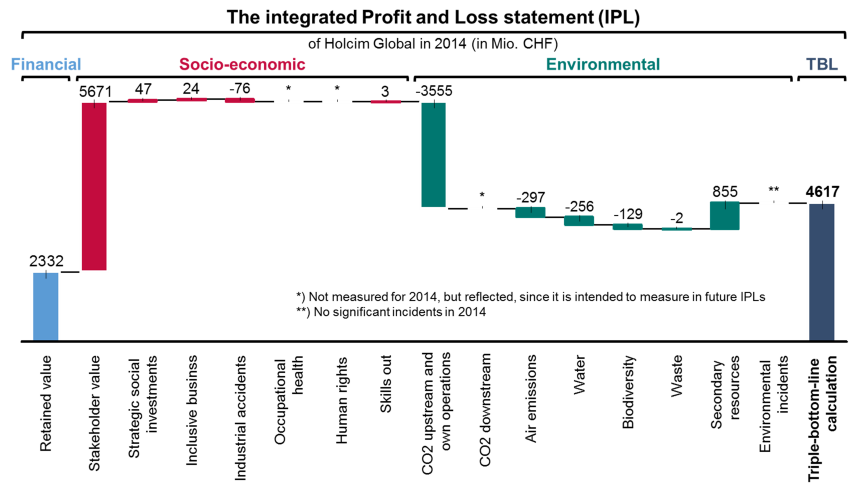

Fig. 3. The integrated profit and loss statement (IPL) of Holcim Global (Source: [14])

that aim to design tools for sustainability assessments, funded by the European Union" [16]: (i) EFORWOOD (Sustainability Impact Assessment of the Forestry-Wood Chain); (ii) SENSOR (Sustainability Impact Assessment: Tools for Environmental, Social and Economic Effects of Multifunctional Land Use in European Regions; (iii) SEAMLESS (System for Environmental and Agricultural Modelling, Linking European Science and Society); (iv) MCPFE C\&I (Ministerial Conference on the Protection of Forests in Europe Criteria and Indicators); and the EUROSTAT (Sustainable Development Indicators SDI). However, except for the EUROSTAT SDI, these are mainly sector-specific and even the EUROSTAT SDI has to be extended to apply it for a specific sector (as has been done by EFORWOOD, which uses it as a basis [16]).

Within the life cycle sustainability assessment (LCSA) Sutherland et at. present a number of tools (and its associated principles and methods) related to life cycle assessment (LCA) and life cycle costing (LCC) across the three dimensions of sustainability [2]. An overview of these tools and the links are shown in Figure 4. While there are well-established tools like LCA available for the environmental dimension, there is "still need for consistent and robust indicators and methods" for the economic and social dimension [7]. Efforts have been undertaken for deter-mining a functional unit to measure environmental performance in manufacturing systems (e.g., [19]) and integrating Life Cycle Assessment with common economic evaluations in order to increase the eco-efficiency (e.g., [20]). Still, especially the social life cycle assessment (sLCA) is considered to be in its infancy [21]. Like there has been a vast amount of research with regards to eco-efficiency in the last decades, there are still a variety of unsolved problems when explicitly considering the social dimension. In future, "focus needs to be placed on methods to quantitatively capture the social impacts of manufacturing" and also continue improving economic and environmental performance measures in this context [22] Overall, only a few of the international efforts on measuring sustainability "have an integral approach taking into account environmental, economic and social aspects" [23]. In addition, many of these efforts 


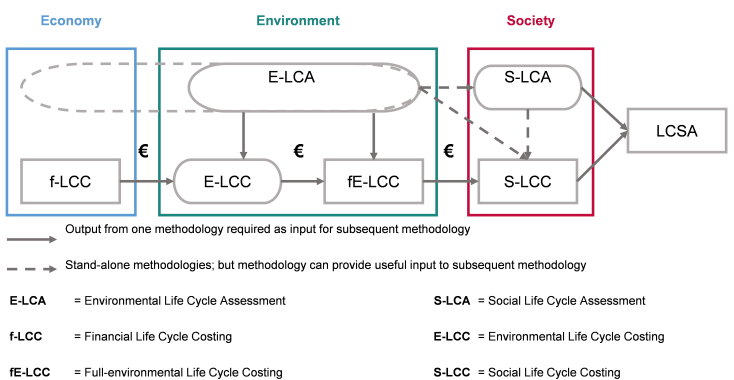

Fig. 4. Links of different sustainability assessment tools (Source: adapted from $[17,18,2])$

currently still remain at the conceptual level and comprehensive, standardized approaches applicable to globally acting companies in different sectors still need to be developed.

\section{Conclusions and Outlook}

In order to address the integration of the social dimension with the economic and environmental dimensions of sustainability, the three perspectives "cost", "result" and "life-cycle" are presented. For each perspective associated approaches are introduced, namely total cost of ownership (TCO), triple bottom line (TBL) and life-cycle assessment (LCA). Examples from industrial practice are provided in order to illustrate how manufacturing companies implement the integration of social and environmental dimensions on sustainability in varying degrees of detail and at different system levels. Still, practical challenges with regard to indicator selection and weighting issues remain unsolved. The need for future research activities consists in e.g. collecting data or selecting impact categories/stakeholder groups. In order to raise a higher awareness of the full spectrum and importance of sustainability, it is of utmost importance to create comparable and standardized performance measurement systems. This will increase the transparency and will therefore help managers as well as customers to make better (i.e. more sustainable) decisions.

\section{References}

1. Rippel, M., Willner, O., Plehn, J., Schönsleben, P.: Bridging the Gap between Energy Management Systems and Machine Tools-Embedded Energy Efficiency in Production Planning and Control. In: IFIP International Conference on Advances in Production Management Systems. pp. 80-87. Springer (2012)

2. Sutherland, J.W., Richter, J.S., Hutchins, M.J., Dornfeld, D., Dzombak, R., Mangold, J., Robinson, S., Hauschild, M.Z., Bonou, A., Schönsleben, P., others: The Role of Manufacturing in Affecting the Social Dimension of Sustainability. CIRP Annals-Manufacturing Technology 65(2), 689-712 (2016) 
3. Bremen, P.M.: Total Cost of Ownership: Kostenanalyse bei der Globalen Beschaffung Direkter Güter in Produzierenden Unternehmen. Diss. ETH (2010)

4. Schönsleben, P.: Integral Logistics Management: Operations and Supply Chain Management Within and Across Companies. CRC Press (2016)

5. Bilharz, M., Schmitt, K.: Going Big with Big Matters. The Key Points Approach to Sustainable Consumption. GAIA-Ecological Perspectives for Science and Society 20(4), 232-235 (2011)

6. Jasinski, D., Meredith, J., Kirwan, K.: A Comprehensive Review of Full Cost Accounting Methods and their Applicability to the Automotive Industry. Journal of Cleaner Production 108, 1123-1139 (2015)

7. Emerson, J.: The Blended Value Proposition: Integrating Social and Financial Returns. California management review 45(4), 35-51 (2003)

8. Finkbeiner, M., Schau, E.M., Lehmann, A., Traverso, M.: Towards Life Cycle Sustainability Assessment. Sustainability 2(10), 3309-3322 (2010)

9. Traverso, M., Finkbeiner, M., Jørgensen, A., Schneider, L.: Life Cycle Sustainability Dashboard. Journal of Industrial Ecology 16(5), 680-688 (2012)

10. Bundesministerium für Arbeit und Soziales: http://www.csr-preis-bund.de/ english-summary.html

11. Ernst \& Young: http://www.ey.com

12. Brown, H.S., de Jong, M., Levy, D.L.: Building Institutions Based on Information Disclosure: Lessons from GRI's Sustainability Reporting. Journal of Cleaner production $17(6)$, 571-580 (2009)

13. Johnson, M.P.: Sustainability Management and Small and Medium-Sized Enterprises: Managers' Awareness and Implementation of Innovative Tools. Corporate Social Responsibility and Environmental Management 22(5), 271-285 (2015)

14. Holcim: http://www.holcim.com

15. Laufer, W.S.: Social Accountability and Corporate Greenwashing. Journal of Business Ethics 43(3), 253-261 (2003)

16. Rametsteiner, E., Pülzl, H., Alkan-Olsson, J., Frederiksen, P.: Sustainability Indicator Development-Science or Political Negotiation? Ecological Indicators 11(1), 61-70 (2011)

17. Kloepffer, W.: Life Cycle Sustainability Assessment of Products. The International Journal of Life Cycle Assessment 13(2), 89-95 (2008)

18. Hoogmartens, R., Van Passel, S., Van Acker, K., Dubois, M.: Bridging the GAP Between LCA, LCC and CBA as Sustainability Assessment Tools. Environmental Impact Assessment Review 48, 27-33 (2014)

19. Plehn, J., Züst, R., Kimura, F., Sproedt, A., Schönsleben, P.: A Method for Determining a Functional Unit to Measure Environmental Performance in Manufacturing Systems. CIRP Annals-Manufacturing Technology 61(1), 415-418 (2012)

20. Sproedt, A., Plehn, J., Schönsleben, P., Herrmann, C.: A Simulation-based Decision Support for Eco-efficiency Improvements in Production Systems. Journal of Cleaner Production 105, 389-405 (2015)

21. Hunkeler, D.: Societal LCA Methodology and Case Study (12 pp). The International Journal of Life Cycle Assessment 11(6), 371-382 (2006)

22. Haapala, K.R., Zhao, F., Camelio, J., Sutherland, J.W., Skerlos, S.J., Dornfeld, D.A., Jawahir, I., Clarens, A.F., Rickli, J.L.: A Review of Engineering Research in Sustainable Manufacturing. Journal of Manufacturing Science and Engineering 135(4), 041013 (2013)

23. Singh, R.K., Murty, H., Gupta, S., Dikshit, A.: An Overview of Sustainability Assessment Methodologies. Ecological Indicators 15(1), 281-299 (2012) 